\title{
Emociones, masculinidad y sexualización. Investigar sobre mercado sexual en Argentina
}

Emotions, Masculinity and Sexualization in the Fieldwork. Researching Sex Markets in Argentina

\author{
Santiago Morcillo ${ }^{1}$ \\ ${ }^{1}$ Consejo Nacional de Investigaciones Científicas y Técnicas (CONICET) \\ santiagomorcillo@gmail.com
}

Fecha de recepción: 7 de junio de 2019

Fecha de aceptación: 31 de octubre de 2019

\section{Resumen}

El presente trabajo plantea una reflexión sobre el papel de las relaciones de género, las masculinidades y las formas de sexualización en la investigación social. El contexto actual de expansión de los feminismos -globalmente, pero en Latinoamérica y Argentina puntualmente- amplifica el foco sobre las dimensiones sexuadas y generizadas de la investigación y, a la vez, pone de relieve un conjunto de tensiones en las relaciones de poder y afectos en el trabajo de campo. Tomando en cuenta este marco, aquí reflexiono sobre el trabajo de campo en dos investigaciones: una de varios años entre mujeres que ofrecen sexo comercial y otra, más reciente, sobre varones que pagan por sexo. Ambas investigaciones funcionan como una contracara. Ello me permite hacer foco en las interpelaciones sexuales, generizadas y el terreno de las emociones -entendido como un espacio que permite unir significaciones y cuerpos-, para intentar una lectura situada que ponga en juego las intersecciones de las perspectivas metodológica, epistemológica y política.

Palabras clave: género, sexualidad, prostitución, reflexividad, trabajo de campo.

\begin{abstract}
This paper presents a reflection on the role of gender relations, masculinities and forms of sexualization in social research. The current context of expansion of feminisms -particularly in Latin America and Argentina- amplifies the focus on the sexed and generated dimensions of research. Moreover, this conjuncture time highlights a set of tensions in power relations and affections in fieldwork. Taking into account these points, analysis is based on fieldwork from two investigations: one with women who offer commercial sex and other about men who pay for sex. I focus on sexual and gendered interpellations and the field of emotionality -understood as a space that connects meanings and bodies-, to essay a situated reading intersecting the methodological, epistemological and political perspectives.
\end{abstract}

Keywords: gender, sexuality, prostitution, reflexivity, fieldwork.

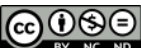

Este obra está bajo una licencia de Creative Commons Reconocimiento-NoComercial-SinObraDerivada 4.0 Internacional. 


\section{Introducción}

Cuando iniciaba mi doctorado cursé el primer "Taller de tesis», allí buscábamos clarificar nuestras ideas -o al menos disminuir la confusión inicial- para poder conducir nuestras investigaciones y lograr arribar a una tesis. En una de las primeras clases tuve una experiencia desconcertante que luego me daría mucho que pensar: tras escucharme esbozar lo que sería mi tema de tesis («las experiencias de mujeres en prostitución»), el profesor bromeó con una sonrisa socarrona sobre lo «divertido» que me sería «salir de trabajo de campo». Este sería el preanuncio de un asunto que, aunque volvería repetidas veces, pocas personas tomaban en serio y solo parecía ser un chiste.

Hace tiempo que los estudios de género y sexualidades vienen cuestionando la concepción objetivista que invisibiliza las posiciones de sexo-género y los cuerpos de quienes investigan. Actualmente, la expansión de los feminismos (globalmente, pero en Latinoamérica y Argentina puntualmente), las reivindicaciones ligadas a las inequidades de género $\mathrm{y}$, al mismo tiempo, la creciente sexualización de la cultura, amplifican el foco sobre las dimensiones corporales, sexuadas y generizadas de la investigación. A su vez, esta coyuntura pone de relieve tensiones en las relaciones de poder y de afectos en el trabajo de campo.

Estos debates, en sus implicancias metodológicas, epistemológicas y políticas, no son exclusivos de los estudios sobre género y sexualidades. El autor de una de las etnografías más celebradas en las últimas décadas ha señalado las tensiones éticas que atraviesan este método: desde el nivel de las restricciones que suponen las normas institucionales ${ }^{1}$ para investigar sujetos que sufren marginación u opresión, hasta la consideración del papel de los afectos entablados en el campo en la producción de conocimiento (Bourgois 1990; 2010). La tensión más evidente y más tematizada en este último aspecto tiene que ver con la posibilidad de entablar vínculos que usen los afectos en el campo de forma cínica y expoliativa. Mucho menos problematizado es el riesgo de romantizar esos vínculos de forma tal que se pierdan de vista tanto las asimetrías estructurales como las propias contradicciones de las personas que actúan como informantes y con quienes investigamos. A su vez, las discusiones sobre cómo investigar con sujetos en posiciones de subalternidad han ocupado mucho más espacio que la reflexión sobre la ética y la emocionalidad en los vínculos de investigación con sujetos en otras posiciones.

Tomando en cuenta estos puntos, en este texto reflexiono sobre mis experiencias de trabajo de campo en dos líneas de investigación: una, de hace algunos años, entre mujeres que ofrecen comercio sexual y otra, más reciente, sobre varones que pagan por sexo. Para iniciar, reviso algunos nudos en los debates sobre las posiciones sexo-generizadas de quienes

\footnotetext{
${ }^{1}$ Se refiere a los temidos «comités de ética» y sus normativas que se han desarrollado con fuerza especialmente en el contexto anglosajón.
} 
investigan, así como el papel de las emociones y afectos. A continuación recorro algunos puntos clave de mi trabajo de campo en ambas investigaciones: las formas de acceso, las interpelaciones sexuales, generizadas y el terreno de la emocionalidad, entendido como un espacio que une significaciones y cuerpos (Hochschild 1979). Retomo aquí un trabajo previo (Morcillo 2010) para complejizar mis propias posiciones, tomando en cuenta tanto nuevas investigaciones y experiencias como investigador, como los cambios en las coyunturas actuales. Intento así una lectura situada que ponga en juego perspectivas metodológicas, epistemológicas y políticas para interpretar estas experiencias y lanzar nuevos interrogantes.

\section{El largo camino de la reflexividad hasta debajo de la cintura}

Hace ya varias décadas se comenzó a reflexionar críticamente sobre la posición de quienes investigamos. En este proceso la crítica de la ligazón entre antropología y colonialismo han jugado un papel clave poniendo en cuestión las relaciones sociales de poder que atraviesan los vínculos entablados en la investigación. Sin embargo, esta reflexividad demoró en enfocar los aspectos corporales, emocionales y generizados presentes en la producción de conocimiento (y especialmente en el trabajo de campo). Será de la mano de la epistemología feminista, con su crítica hacia el objetivismo totalizante y la propuesta del «conocimiento situado», que se empieza a tener en cuenta el carácter «parcial» de todas las posiciones (Haraway 1995). Más tardío todavía fue el análisis de la dimensión sexualizada y del erotismo en la investigación. Si bien en Latinoamérica algunas etnografías sobre mercados sexuales - como aquella de Néstor Perlongher (1993)- ya habían dejado entrever la dimensión problemático-productiva de la sexualización en el trabajo de campo a mediados de los 80; en la bibliografía del norte global no será hasta la década siguiente que veremos surgir con fuerza debates centrados en este asunto (Kulick y Willson 1995; Markowitz 2003; Newton 1996; Sanders 2006; O'Connell Davidson 2008).

En este derrotero, la reflexión epistemológica (y política) hizo posible repensar la propia metodología y las implicancias de los vínculos que entablamos en el campo. Por ejemplo, se ha interrogado el espacio de las entrevistas como una forma de relación paternalista, especialmente cuando se entrevista a mujeres, según señalan Fontana y Frey (1994). Un hito en este debate fue el profusamente citado Interviewing women, de la británica Ann Oakley (1981). Allí se planteaba que la entrevista responde a un paradigma masculino que apunta a la producción de datos, pero sin reconocer el vínculo en la entrevista en tanto el investigador se mantiene distante y sin mostrar sus emociones ni sensibilidad. Para Oakley (1981) esta distancia, presente por ejemplo cuando no se contestan las preguntas o las interpelaciones de las personas informantes, no solo debilita la confianza, sino que puede transformarse en algo

\section{(c) (1) (8) $\odot$}


poco ético cuando hay una experiencia compartida (la de la maternidad en su caso) ${ }^{2}$. Por contrapartida se pensaba la entrevista como una «transición hacia la amistad» y así la investigación feminista aparecía como un espacio no jerárquico y empoderante, donde se tomaba en cuenta la reciprocidad. En la cresta de la segunda ola feminista parecía haberse cimentado un sentido común sobre «la entrevista feminista» (Warren 2001).

Algunos años luego comenzaron a emerger las críticas y matizaciones de esta concepción de la entrevista (reconocida como nä̈ve por la propia Oakley 2016). Esta concepción presupone que entrevistada y entrevistadora comparten género, socialización y experiencias de vida críticas como presupuesto para establecer la situación de entrevista como encuentro no jerárquico y no expoliativo (O'Connell Davidson y Layder 1994). La perspectiva que subyace aquí, como señalaron las críticas poscoloniales y queer de los 90, hace caso omiso de las diferencias de clase, raza, edad y sexualidad; al tiempo que esencializa la feminidad. En contraste, varios estudios sobre varones plantean las dificultades que suponen estas relaciones de investigación (Grenz 2005; Flood 2013). Algunas investigadoras admiten haber manipulado a sus entrevistados para obtener respuestas ${ }^{3}$. A pesar de lo controversial de este tratamiento, estas investigaciones permiten poner en cuestión el modelo que busca simplemente «dar voz» a quienes actúan como informantes, y ponen de relieve la necesidad de hacer un análisis crítico de sus discursos. Entonces, surgen preguntas como: ¿qué significado tienen estos aportes para pensar el lugar de los varones como investigadores? ¿qué sentido tienen para las investigaciones en el llamado «sur global», donde las relaciones de investigación suelen ser distintas?

Parte de nuestro posicionamiento en el campo incluye también tener en cuenta el contexto geo-político. Por ejemplo, la concepción del colonialismo como un rasgo inherente a las relaciones con informantes oblitera la posición específica de quienes hacemos ciencias sociales en el sur global. Esta especificidad es omitida y se reproduce la retórica que critica las relaciones entre académicos e informantes en el norte global, con otra historia y otras condiciones de posibilidad (una última colonización a la que también pueden colaborar las y los nativos en el sur). En el contexto local, la afectividad y politización de las investigaciones aparecen con frecuencia, especialmente en el campo de las investigaciones sobre sexualidad, tensionando la pretendida autonomía del quehacer científico. Sin embargo, en Argentina, la posición generizada y sexuada de quienes investigan no ha sido un tema central para muchos trabajos, sino más bien algo infrecuente (especialmente cuando se trata de varones) (Pecheny, Manzelli y Capriati 2010). Esta ausencia va de la mano con la concepción que, en el intento de escapar de la tradición objetivista, ha pasado a pensar la producción científica como una

\footnotetext{
${ }^{2}$ Oakley (2016) recuerda que uno de los disparadores para escribir su artículo fue la inquietud que le produjo el caso de una entrevistada que le preguntaba, en el marco de una investigación sobre maternidad, «de qué agujero» saldría el bebé que estaba por parir.

${ }^{3}$ Por ejemplo, Diane Scully relata que, para entrevistar a varones condenados por violación, no solo impostaba una fachada emocional falsa, sino que ocultaba aspectos de la información sobre su investigación y limitaba la confidencialidad de los relatos (citada en O'Connell Davidson y Layder 1994)
} 
posibilidad para dar voz a quienes están en posición de subalternidad, confundiendo «las voces y los portavoces» (Pecheny 2008, 9). A su vez, este gesto veladamente vanguardista, que niega el papel de quien investiga como intérprete y traductor, puede llevar a representar a quienes no desean representación (Figari 2011).

¿Podemos buscar un punto de partida que, sin omitir el rol de ninguna de las partes, haga posible pensar la afectividad y las emociones en el marco del trabajo de campo como formas de generar puentes entre subjetividades situadas? Situarse implica posicionarse en el mapa social y en el campo desde el cuerpo, entonces «la relación de investigación siempre va a ser cuerpo a cuerpo, no importando qué cuerpo, es decir, como un lugar y no una esencia; como el 'carácter situado de una mirada'» (Figari 2011,4). Desde allí me interesa reflexionar sobre lo que Figari llama una «posición amorosa» centrada en el otro o, siguiendo a Evelyn FoxKeller, una «percepción alocéntrica» que recupera la pulsión amorosa, origen emocional de la actividad científica y estética: Una percepción alocéntrica se relaciona con el cuidado del otro (que no se resuelve tan simplemente con un consentimiento informado contractual). No se propone «sacar» información, pretende producirla. Acompaña, escucha, da soporte y soporta, ríe, pone el hombro, abraza, guarda silencio, habla, transmite o comunica y si es necesario, no dice nada (Figari 2011, 10).

Ahora bien, esta posición, como ha sido señalado (Irwin 2008, Dubisch 1995, O'Connell Davidson 2008) -y como me demostró mi propia experiencia-, abre un conjunto de problemas frente a los cuales la formación tradicional en metodología de ciencias sociales prepara de forma bastante escueta -acaso solo dictando que se debe «lograr un buen rapport» y sin explicar mucho más al respecto-- Señalaré dos aristas que se ligan con las investigaciones en el mercado sexual y sobre las que volveré más adelante.

Por una parte, emerge la cuestión del consentimiento informado como un procedimiento insuficiente para el cuidado. O'Connell Davidson (2008) señala una diferencia entre consentimiento y cuidado (care), donde el primero implica una relación contractual en el sentido liberal; el segundo implica la vulnerabilidad de las personas informantes y presupone que pueden no conocer sus propios intereses. A su vez, el cuidado en las relaciones de investigación pone de relieve otros problemas frente a la publicación y circulación de resultados: las limitaciones, tanto para quienes investigan como para quienes actúan como informantes, en relación a la previsibilidad de los efectos de la investigación (tanto gratificantes como aquellos más problemáticos), y el tiempo que implica una relación de investigación a largo plazo, pues como indica O'Connell Davidson a veces investigamos con sujetos con quienes no podemos o no queremos tener una relación de ese tipo. ¿Cómo pensar el cuidado y la «posición amorosa» en las relaciones de investigación frente a los devenires erotizantes, sexualizantes y/o romantizadores de esa afectividad? ¿Debemos remitirnos a la idea de la «transferencia» psicoanalítica, pensada como escena amorosa radicalmente restringida donde se «inmoviliza el cuerpo para poder hablar» (Butler 2002, 62)? ¿Es posible demandar esta inmovilidad a quienes actúan como informantes? Aun así, no solo el deseo 
erótico, sino también las relaciones afectivas de cierto grado de intimidad han probado ser un desafío para quienes investigan; y dar lugar a quienes actúan como informantes en la investigación, como forma de desplazarse de la relación más jerarquizada y limitada, también introduce otras dificultades (Irwin 2008; O'Connell Davidson 2008).

La falta de problematización de las dimensiones sexuales y eróticas de la investigación en el campo, colaboraba a instituir como mirada pretendidamente neutral a aquella del varón blanco cisgénero heterosexual (Newton 1996). Con el giro intimista de los 90 se cuestionó el «tabú» de la sexualidad en el trabajo de campo y el mandato hegemónico de celibato para quienes hacen etnografía, pues no solo partía de un prejuicio objetivista, sino que también operaba como forma de mantener a salvo el self del investigador. En cambio, se proponía «poner en juego el self» de quien investiga (Kulick y Willson 1995) y así se abrieron algunos permisos para discutir sobre el asunto. Algunos han reivindicado el papel productivo del sexo en el campo, por ejemplo, como la única forma de lograr producir ciertos datos en los lugares de cruising (Langarita Adiego 2017), o sostenido que una buena relación sexual (good sex) instaura un lazo profundo con las personas informantes, habilita una mayor intimidad y así permite transponer límites a la información, como afirma Ralph Bolton (1995) respecto a su trabajo de campo, también vinculado a prácticas homosexuales. Otras veces, se ha sugerido que puede no ser necesario entablar relaciones sexuales; pero mostrarse como una persona sexualizada puede servir para entablar un «nexo natural» entre informantes y quienes investigan -aun cuando estos sean varones blancos y heterosexuales- (Markowitz 2003).

Pero, una vez más, si se acepta la premisa de colocarse en la investigación como ser sexuado, luego se abren las difíciles preguntas sobre cuándo y cómo autorizarse a entrar en el juego de deseos, cómo manejar las interpelaciones sexualizantes, cuándo y cómo abrir la propia biografía (en el campo y en el texto). A pesar del entusiasmo por explorar las emociones y la sexualización en el campo, varios de estos trabajos dejaban entrever los temores y los riesgos implicados ¿En qué medida y/o de qué formas se ha transformado (o no) esta situación? Tomando en cuenta que desde los 90 hemos asistido a una expansión radical del feminismo (y del feminismo radical) y a una re-tematización de la sexualidad en torno a la violencia ¿qué nuevos sentidos adquieren las emociones y el erotismo en el trabajo de campo? Cada experiencia, cada campo de investigación y cada coyuntura presentan sus particularidades, empecemos entonces desde allí.

\section{Investigando con mujeres que hacen comercio sexual}

Antes de comenzar el trabajo de campo con mujeres que hacen comercio sexual (desarrollado entre 2008 y 2012), era consciente de que las relaciones de investigación con personas estigmatizadas, de clases populares y/o que mantienen algún secreto suelen presentar problemas de accesibilidad y/o rechazos (Adler y Adler 2001); y este es el caso de las mujeres en el comercio sexual. Además, el marco legal en Argentina hace que buena parte

\section{(c) (1) $\$(-)$}

Este obra está bajo una licencia de Creative Commons Reconocimiento-NoComercial-SinObraDerivada 4.0 Internacional. 
de este sector esté ligado a situaciones ilegales y/o clandestinas. Otro problema fue el enfrentamiento entre las organizaciones de mujeres que hacen comercio sexual, siguiendo la polarización del debate feminista sobre la prostitución ${ }^{4}$ : una organización se posiciona como abolicionista y otra como pro-derechos de las «trabajadoras sexuales». El acceso a través de las organizaciones fue un sendero estrecho e implicaba repetidos escrutinios acerca de los objetivos de mi investigación y, buscando saber -más o menos veladamente- cómo me posicionaba respecto al debate.

En este contexto, persuadido por la afirmación de Perlongher, «no hay mejor manera de estudiar el callejeo que callejeando» $(1993,20)$, deambulé («yiré») por diversos escenarios. En las calles y los cabarets realicé aproximaciones sucesivas a partir de la observación en terreno en distintas localizaciones siguiendo también la idea del «vagabundeo» ${ }^{5}$. Esta aproximación mostraba que, en primera instancia, mi posición como varón presuntamente heterosexual, facilitaba una entrada al campo, aunque de cierta forma particular. En un contexto de comercio sexual nadie cuestiona «¿qué hace un varón acá?» ${ }^{6}$. Un varón estaría comparativamente menos expuesto a sucesos violentos de lo que suelen estar las mujeres (Nilan 2002), pero también -en contraste con las investigaciones conducidas por mujereslimitado para comentarios respecto a algunas cuestiones de embarazo, higiene femenina y menstruación (Gaspar 1985). Cada posición tiene sus puntos dilemáticos, más o menos variables: para algunas mujeres investigadoras puede aparecer el dilema sobre si hacer observación participante implica directamente hacer comercio sexual (Sanders 2006; O’Connell Davidson 2008), para los investigadores varones la disyuntiva sería si participar implica transformase en clientes. Es justamente esta potencialidad de tornarse clientes la que garantiza un acceso menos problemático, pero acarrea otros conflictos.

¿Cómo se abre el juego al entrar en los espacios de comercio sexual? ¿Cuál es la primera aproximación para interactuar en el campo? La importancia de la mirada es clave en el contexto de comercio sexual. Para Perlongher «el golpe de vista de la prostituta [...] sexualiza y enciende la muchedumbre anodina» $(1993,128)$ y, dentro del «dispositivo de prostitución», funciona como una máquina de captura, pues rápidamente reconvierte ese deseo encendido en cantidades medibles de dinero. La mirada es imprescindible para interpretar tanto que una mujer está ofreciendo comercio sexual -pues en las calles o plazas, esto no siempre es

\footnotetext{
${ }^{4}$ Utilizo alternativamente «prostitución» o «comercio sexual» según el aspecto a enfatizar. El primer término habilita poner de relieve la estigmatización y/o la forma de denominación históricamente más extendida; por otra parte, «comercio sexual» me permite una aproximación más analítica a la práctica (para una reflexión sobre la idea de «trabajo», ver Morcillo 2014).

${ }^{5}$ Entiendo el vagabundeo como «un acercamiento de carácter informal, incluso antes de la toma de contacto inicial, al escenario que se realiza a través de la recogida de información previa sobre el mismo: qué es lo que lo caracteriza, aspecto exterior, opiniones, características de la zona y entorno, etc.» (Gómez, Flores, y Jiménez 1996, 72)

${ }^{6}$ Investigar sobre comercio sexual puertas adentro parece menos accesible para investigadoras mujeres, también puede implicar interpelaciones sexuales de los varones clientes (cfr. Justo y Morcillo 2011)
} 
inteligible a partir de la vestimenta o de las posturas corporales-, como que un varón está queriendo comprar lo que ella ofrece. En el contexto del comercio sexual, las marcas de masculinidad que hacen legible un cuerpo como varón y heterosexual, aumentan su potencialidad como cliente. Aquí, la pretensión de que los investigadores sostengan una mirada supuestamente neutral -y para ello descorporeizada- se hace (evidentemente) insostenible.

Incluso para quienes no habitan los espacios de comercio sexual, el significado de un cuerpo de varón en este marco parece autoevidente. Por ejemplo, como señalé al principio, al comentar sobre mi investigación aparecía siempre una presuposición de que el trabajo de campo consistía en «ir de putas». Esta presunción se repetía (y se repite) muchas veces bajo la forma de chistes, sin importar el género de mis interlocutores, fuera y dentro del ámbito académico. Algo de estas «bromas» me mostraba la ubiquidad de la presunción y a la vez la imposibilidad de abordar frontalmente la cuestión de la sexualización en el trabajo de campo.

Tanto por la dinámica específica del campo como por el sentido común, el principal peligro parecía ser la asimilación con el rol de cliente. ¿Por qué entendí esto como un peligro? En primer lugar, podía suponer ocultar mi investigación. Algunos enfoques conciben la posibilidad de usar métodos encubiertos, sin embargo, desde el posicionamiento que fui construyendo para esta investigación, entendí que esto alimentaría una forma de construir conocimiento desde el distanciamiento (y la expropiación) ${ }^{7}$. Además, la posición de varóncliente implicaba ponerme en una situación complicada si algún varón-cliente con expresiones misóginas me reclamaba complicidad, dándome más motivos -no solo metodológicos, sino ético-políticos- para distanciarme de la posición de cliente cuando asume estas características. Finalmente, investigar desde el rol de cliente hubiera sido un obstáculo para mis propios objetivos de investigación, donde las relaciones de poder entre los clientes y las mujeres que hacen comercio sexual ocupaban un papel importante. Quedar en la posición de cliente implicaba que me hubiera sido inaccesible cierto «discurso oculto» (Scott 2000). Frecuentemente quienes hacen comercio sexual usan tácticas que buscan anticipar los sentidos y dirigir la interacción con los clientes, por ejemplo, el «chamuyo» (verborragia no exenta de engaños). Entablar las relaciones de investigaciones desde el lugar de cliente no supone más intimidad, pues justamente buena parte del saber hacer, adquirido en las experiencias de las mujeres en el comercio sexual, consiste en segregar a los clientes de su intimidad (Morcillo 2011). Si bien existen otro tipo de vínculos con algunos clientes, estos son posibles solo bajo ciertas condiciones, entre ellas una duración de varios años (Morcillo 2017a). Entonces, el camino para lograr intimidad, en un vínculo de comercio sexual, resulta mucho más difícil y personalmente cargado de contradicciones. En el corto y

\footnotetext{
${ }^{7}$ Varios textos han tratado la cuestión de los métodos encubiertos, y una investigación sobre sexualidad es un ejemplo frecuente en estas discusiones: el estudio de los tearooms de Laud Humphreys (1974) donde el investigador no solo mantuvo ocultas las intenciones de su estudio como forma de garantizar la accesibilidad, sino que trianguló su información con datos policiales para rastrear a sus informantes (Ver también distintas posiciones sobre esta investigación en Adler y Adler 2001, Langarita 2017).
} 
mediano plazo, identificarme como cliente habría complicado la posibilidad de un vínculo empático y afectivo.

Los intentos por desplazarme de la posición de cliente estaban supeditados a factores propios de la dinámica de los espacios de comercio sexual. Uno de ellos era la constante confusión entre mi interés por lograr interactuar, conversar, entablar vínculos y el interés sexual. En este sentido, me vi obligado a no rechazar de antemano el juego de seducción y, a la vez, tampoco involucrarme demasiado en él. La seducción en este contexto es más bien parte del negocio y no una forma de ganar intimidad. Las investigaciones en escenarios de seducción atraviesan el desafío de las similitudes entre la aproximación desde el deseo erótico, la búsqueda del famoso rapport y la proximidad que se debe generar en el trabajo de campo (Lacombe 2009). Andrea Lacombe retoma la teoría de la performatividad del lenguaje para comprender por qué sus intentos de esquivar la interacción erótica en discotecas LGBT eran desdeñados o incomprendidos. Esta falla del no, la pérdida de carga semántica de la negación, significará una apertura de los sentidos sobre la posición subjetiva y, a la vez, una constante ambigüedad en la mirada de quienes actúan como informantes.

Asimismo, cuando abandonaba la «bola de nieve»e intentaba nuevas líneas de contacto («saltar el cerco»), lo hacía usando canales utilizados también por los clientes, lo que demandaba reforzar los intentos por distanciarme de esa posición. Kevin Walby (2010), en una investigación sobre varones trabajadores sexuales, plantea que contactar a sus entrevistados por canales similares a los de los clientes alimenta la sexualización de los encuentros de entrevista. Sin embargo, Walby también remuneraba a sus entrevistados como forma de obtener las entrevistas. En mi investigación consideré pagar compensaciones en dinero a cambio de las entrevistas, aunque lo terminé descartando por la falta de recursos que me permitieran pagar montos apreciables para las entrevistadas (en particular para las «escorts»o «prostitutas vip»). Pero además, el pago por las entrevistas en el contexto del comercio sexual puede significar la mercantilización del vínculo con las entrevistadas (Russo 2008), y el riesgo de la asimilación con un cliente aumentaba. Por contrapartida, como advertiría más tarde, la ausencia de dinero y la circulación de afecto puede presentar el peligro de la romantización de esa relación -los olvidos de las posiciones estructurales, las contradicciones y la materialidad de los intercambios-, algo que resulta particularmente problemático en el campo del mercado sexual (Morcillo 2017a).

También el espacio donde ocurren los encuentros condiciona los sentidos que pueden atribuirse a la interacción. En el contexto de calle, aun en una «zona roja», hay mayor circulación de personas y de sentidos para connotar la interacción. Esto me habilitó a trabajar sobre mi apariencia e incluso llevar visiblemente una carpeta, papeles y lapicera que daban, ya desde antes de abrir el diálogo, algunas señales de qué es lo que estaba buscando en esas interacciones, adónde se dirigían mis miradas. Sin embargo, las preguntas muchas veces fluían en ambos sentidos, tras lograr un acercamiento y un buen rapport con las entrevistadas (especialmente las travestis y algunas mujeres más jóvenes). La seducción, las 
interrogaciones e interpelaciones eróticas se reinauguraban tras apagar el grabador -que funcionaba como parte de mi «traje» de investigador, junto con mis papeles y carpeta-. En los contextos de comercio sexual puertas adentro ya no había lugar para los elementos de mi atuendo que me diferenciaban de los clientes. Además, estos escenarios de comercio sexual se hallan vigorosamente heterosexualizados y prima una presunción sobre el deseo sexual de cualquier varón que allí de encuentre.

Distanciarme de la posición de cliente no significó tener otro rol claro, sino que me empujó a reflexionar sobre cómo podía, desde mi posición subjetiva, entablar los tipos de vínculos que alimentaran la comprensión en el contexto del comercio sexual. El planteo y las dudas iniciales sobre si podría o no ser un cliente, me permitieron no solo clarificar metodológicamente mi posición como investigador, sino reflexionar también sobre mis propias significaciones en torno a las prácticas sexuales, asociadas al deseo erótico, el afecto y la reciprocidad. Tomar en cuenta mis concepciones, cuestionarme e interrogarme al respecto, me habilitó una comprensión más cabal del trabajo emocional y de reelaboración de sentidos que supone dedicarse al comercio sexual.

El rumbo se esclarecería no solo desde la introspección y el cuestionamiento de mi lugar, sino fundamentalmente en la propia interacción en el campo y la reflexión constante sobre dichos eventos. La inicial sexualización de los espacios de comercio sexual es, hasta cierto punto, inevitable, especialmente en los lugares cerrados donde circulan mujeres desnudas o en ropa interior. Sin embargo, en un momento logré descentrarme del lugar de varón/cliente y comencé a ver esa sexualidad como una performance laboral. Este proceso se acompañó de cierta resignificación de mi masculinidad. Emergían así insinuaciones y chistes sobre temas sexuales o mi orientación sexual, preguntas y pedidos de hablar «de igual a igual» sobre mi sexualidad. Aprender cómo entender y responder en estos momentos significó poder establecer otros lazos con muchas de estas mujeres. A medida que fui adentrándome en el campo, pude notar que se abría una dimensión de intimidad no sexualizada, por ejemplo, cuando algunas entrevistadas expresaban que después de haber charlado largamente conmigo no podrían tenerme como cliente. En esas ocasiones ocupé un lugar distinto, marcado por las interpelaciones que daban por sentado mi deseo homosexual o por las dudas que despertaba mi expresión de género «poco masculina».

En el campo se conjugan las miradas, las llamadas, el acercamiento y demás formas de interacción que son connotadas con sentidos eróticos o no, según un conjunto de factores que van desde algunos más estructurales, como la posición de sexo-género (y también la clase, la edad y la raza, entre otras); hasta variables más coyunturales, como si la interacción ocurre en un contexto de calle o puertas adentro. Los sentidos preestablecidos se pueden consolidar o poner en cuestión en el devenir de la interacción.

Al abrir mi propia posición y atender a las respuestas (y preguntas) que esta generaba, se ponían en entredicho, al menos circunstancialmente, las identidades de cliente-prostituta. 
En ocasiones esto también significaba compartir mi propia intimidad. El posicionamiento que habilita la entrada de los afectos y emociones en el marco de las entrevistas no tenía que ver con un gesto compasivo, sino que ensamblaba con la concepción epistemológica de la investigación, que supone la creación de conocimiento como un trabajo intersubjetivo, más que una oposición sujeto-objeto. Justamente una entrevistada fue la que me hizo notar esto cuando, luego de una entrevista cargada de emociones e incluso lágrimas, se interesó con mayor profundidad por los objetivos de mi investigación y luego por otros aspectos de mi vida.

Al mismo tiempo, la apertura de las emociones y los afectos en las relaciones de investigación involucra varios riesgos, uno de ellos se liga al olvido de las diferencias estructurales en esos vínculos. La romantización, como efecto de vínculos cargados de afectos, opaca las asimetrías y a la vez produce idealizaciones como una imagen unificada del self. La confianza emergente de las emociones compartidas puede llevar a olvidar que las posiciones estructurales tienen un gran peso y limitan los márgenes de la redefinición de las relaciones de investigación.

Es difícil saber hasta qué punto el artefacto de la entrevista y las relaciones surgidas en el campo habilitaron a resignificar la interpelación como «prostitutas» a las mujeres y mi propio lugar como varón/cliente. Aquí puede resultar útil la categoría de «frecuentadores» acuñada por Elisiane Pasini (2009) para englobar al conjunto de varones que, sin ser necesariamente clientes, transitan por el contexto de comercio sexual y cultivan la homosociabilidad. Esta categoría no excluye a clientes ni potenciales clientes; de hecho, se caracteriza por sus potenciales desplazamientos, «el frecuentador es aquel que tiene la capacidad de movimiento, de transitoriedad» (Pasini 2009, 242). Esta característica tensiona la contraposición entre clientes y los otros tipos de relaciones (novios, amigos, etc.) que suelen plantear las mujeres que hacen comercio sexual. Tal como aprendería a lo largo de los años investigando en el mercado sexual, un cierto grado de potencialidad de cliente siempre ronda a los cuerpos leídos como varones. Más allá del afecto que circule, mi posición en el campo del mercado sexual siempre parece acechada por la imagen del cliente.

\section{Investigando con varones que pagan por sexo}

Antes de comenzar el trabajo de campo con varones que pagan por sexo, este aparecía como relativamente más accesible, dado que el grado de estigmatización de esta población ha sido históricamente menor al de las prostitutas. Sin embargo, al revisar la bibliografía noté que muchos trabajos se referían a los clientes, pero desde las miradas de las prostitutas. El cliente de prostitución ha permanecido durante mucho tiempo como un agente más o menos invisible en el mercado sexual. Ahora bien, en la última década -y en los últimos cinco años en Argentina- esto ha comenzado a cambiar y se han expandido las campañas del feminismo abolicionista que buscan, no solo hacer visible el rol de quienes pagan por sexo, sino hacerlo 
desde la categoría de «prostituyente» de forma estigmatizante (Morcillo, Martynoswkyj y de Stéfano Barbero 2018). Esta transformación marcará el contexto de la investigación.

Prontamente surgirían los interrogantes sobre la validez del enfoque planteado en la investigación anterior. ¿Cuál sería ahora el rol de la conexión afectiva y las emociones en el trabajo de campo con varones, especialmente en los casos de varones que tienen conductas y miradas que podemos ligar a una masculinidad hegemónica? En un principio, el trabajo de campo incluiría únicamente entrevistas a varones que hayan pagado por sexo y una etnografía virtual en foros sobre comercio sexual. A través de los contactos previos con mujeres que hacían comercio sexual, conseguí entrevistar a algunos clientes y a ello se sumaron varios contactos a través de conocidos. Sin embargo, la técnica de bola de nieve, que había tenido algún éxito en la investigación precedente, aquí se mostró mucho menos fructífera. Aquí se puso de relieve que la posición de cliente se halla protegida por el secreto, como respuesta a una potencial estigmatización. Si bien este uso táctico del secreto es compartido por quienes venden sexo (Morcillo 2017b), la capacidad de proteger su información claramente no es la misma. Esta asimetría, además de factores estructurales, se liga tanto a una menor exposición que el mercado requiere a quienes pagan por sexo como a los códigos de silencio masculinos.

Luego de algunos meses, conformé un pequeño equipo para entrevistar a varones que pagan por sexo, se amplió la muestra e incluyó más diversidad de edades, posiciones socioeconómicas y niveles educativos. Los vínculos en las entrevistas fueron, en general, menos tensos de lo que esperaba; pero resultan interesantes los contrastes con las entrevistas realizadas por una socióloga que se integró al equipo ${ }^{8}$. Algunos entrevistados tenían más reacciones emocionales ligadas a la vergüenza o ciertas expresiones de corrección política cuando hablaban frente a una entrevistadora. A su vez, por mi parte, en ocasiones hubo una conexión emocional cuando los entrevistados se permitían cuestionar sus propias formas de masculinidad o se corrían del estereotipo del «macho putañero» (por ejemplo, uno de ellos me comentó emotivamente que hablar en la entrevista le había permitido verse en perspectiva y repensar algunos de sus patrones de conducta). Por contrapartida, la imposibilidad de cuestionar abiertamente los discursos misóginos que aparecían en algunas entrevistas puso a prueba no solo mis capacidades de escucha, sino la fertilidad de construir lazos empáticos como forma de producir conocimiento en las relaciones de investigación para este campo.

Este problema se atenúa de alguna forma en el componente de etnografía virtual. Los foros de internet sobre comercio sexual son espacios de acceso público donde los usuarios opinan e intercambian información sobre comercio sexual. Los dos seleccionados se encuentran online desde 2004 y son los más numerosos de Argentina (tienen más de 200.000 usuarios y varios millones de mensajes cada uno). Si bien cada foro tiene sus reglas, ambos comparten la gratuidad, el objetivo del intercambio de experiencias y un sistema de reputación de los usuarios (de quienes además se muestra su trayectoria de participación). En

\footnotetext{
${ }^{8} \mathrm{Al}$ trabajo de campo en las ciudades de San Juan y Buenos Aires, se agregó la ciudad de Mar del Plata, donde las entrevistas fueron realizadas por Estefanía Martynoswkyj, una becaria doctoral que se incorporó a la investigación.
} 
la sección «Reglas de conducta» de uno de los foros, se describe como «un sitio para intercambiar ideas, para intercambiar experiencias, consultas, pasar buenos momentos y hacerte de buenos amigos que comparten tu misma pasión y, sobre todo, para divertirse». En este espacio de sociabilidad virtual, muchos varones que pagan por sexo comparten sus experiencias ( «XP») por medio de narrativas de sus encuentros con «escorts»; otros piden información sobre un servicio, pero además hay varios hilos sobre «temas generales» donde dialogan sobre cuestiones que muchas veces exceden los encuentros e incluso al mercado del sexo. Allí, insospechadamente, emergen constantemente tópicos que abren a la reflexión y el diálogo entre varones. En buena medida, la clave del éxito de estos foros es la posibilidad de un anonimato bastante bien protegido (considerando lo difícil que esto resulta actualmente). Ese anonimato permite a los usuarios explayarse de formas que, tomando en cuenta las distancias con las narrativas de las entrevistas, probablemente no usarían presencialmente.

La situación de no encontrarme cara a cara con los informantes reducía las incomodidades aparecidas en algunas de las entrevistas. Sin embargo, algunas dificultades aparecieron ligadas con el consentimiento. Además de la enorme cantidad de participantes, la lógica de anonimato y extrema precaución de los usuarios por proteger sus identidades offline, hacen que sea muy complejo, o mejor dicho prácticamente imposible, obtener un consentimiento informado de cada uno de ellos. Los foros, si bien contienen algunos relatos que tradicionalmente se rotularían como íntimos, son de acceso público. Tomando esto en consideración y atendiendo a la lógica de los participantes en el campo, resolví llevar a cabo una observación no-participante y ampliar los mecanismos para proteger el anonimato.

Después de algunos meses de observación en los foros, supe que había grupos en las redes sociales formados como derivado de la participación en los foros y que, eventualmente, organizaban reuniones para socializar. Estos grupos y reuniones abrieron una serie de interrogantes para la investigación: ¿era viable la participación en estas instancias?, ¿de qué formas y bajo qué identidades?

Mientras mi identidad como entrevistador, o como miembro silencioso del foro, no resultaban problemáticas, la interacción en el contexto de las reuniones grupales aparecía acechada por interrogantes de difícil respuesta. La propia dinámica de los participantes, quienes en las reuniones rechazaban utilizar sus nombres y se llamaban solo por sus identidades online (o nicknames), resaltaba la importancia de mantener secretas las identidades personales u offline. De hecho, los participantes solo se conocían por sus identidades online e incluso quienes llevaban varios años en la «comunidad gatera»sabían poco o nada del trabajo y las relaciones familiares de otros, hasta tenían problemas a la hora de ponerle un rostro a los nicknames. A ello se sumaba la volatilidad de estas identidades online, pues es frecuente que los usuarios o perfiles sean borrados, bloqueados o «banneados» por una variedad de motivos, lo cual origina otra fuente de confusión. Si usar un método encubierto puede resultar controversial para la investigación en ciencias sociales, una

\section{(c) (1) () $(-)$}

Este obra está bajo una licencia de Creative Commons Reconocimiento-NoComercial-SinObraDerivada 4.0 Internacional. 
revelación precipitada y directa aparecía como disruptiva en un campo donde la discreción y el secreto sobre las vidas offline y fuera del mercado sexual eran una constante.

A diferencia de la investigación previa, la identidad asociada a una expresión de género que no encaja con los estereotipos de masculinidad donde me había encontrado a mí mismo, no parecía viable ahora para interactuar sin generar disrupciones en un ambiente donde los chistes homofóbicos eran recurrentes. De todas formas, aunque los clientes de prostitución aparecen muchas veces como un conjunto homogéneo, mi trabajo de campo me mostraba algunos matices. Además de temas de conversación tradicionalmente masculinos como automóviles o futbol, en uno de los dos grupos se sumaban chistes y comentarios gordofóbicos, lesbofóbicos y antifeministas. No obstante, el otro grupo al que accedí era más variado con relación a las edades, con mayor participación de escorts en las reuniones e intentaba encuentros más festivos; mientras que el grupo más conservador reunía a varones con promedio de mayor edad en cenas donde las mujeres eran menos y con menor protagonismo en la charla. Si bien este último grupo fue donde encontré los obstáculos más importantes para continuar la investigación dada mi incomodidad e incapacidad de establecer un rapport con los informantes, ambos grupos suponían un desafío a la hora de encontrar «mi lugar».

Varios datos importantes surgían de estas reuniones: la dinámica grupal como activadora formas de masculinidad más jerarquizadoras y ligadas a cierto tipo de masculinidad hegemónica -por comparación con las entrevistas individuales-, la importancia de la sociabilidad entre «gateros» o la distancia que mantenían respecto de sus identidades offline. Pero aquí quiero detenerme sobre los desafíos que me imponía y el trabajo emocional, ahora en un sentido distinto, que debía desplegar a fin de interactuar en esos encuentros.

Si el desarrollo de una percepción alocéntrica y la habilitación del juego de las emociones compartidas, que surgían en la interacción del trabajo de campo, había sido un camino viable y que potenció la primera investigación; este no parecía ser el caso si pretendía investigar en estos grupos de varones. Allí, el mantenimiento de cierta distancia, el trabajo emocional para bloquear la expresión de las emociones que hubieran sido disruptivas y la evitación en algunos momentos parecían ser la forma de (sobre)llevar las interacciones. Ello recuerda la estrategia de «seguir la corriente» (play along) frecuente en el contexto de investigaciones sobre varones sexistas (Flood 2013; Cowburn 2007). Sin embargo, como también señalan los autores, este camino puede habilitar ciertos patrones masculinos de charla, incrementa la apertura para hablar al mismo tiempo que refuerza formas ligadas a una masculinidad dominante.

Las emociones que me disparan las interacciones en estos espacios me permiten construir reflexivamente aspectos de mi posición frente a ciertas formas de masculinidad que emergen -especialmente en contextos grupales- entre varones que pagan por sexo. Para pensar mi posición aquí vuelve a resonar la idea de «frecuentador», recordando que este no 
es nunca un lugar estable, sino una categoría de tránsito que también implica ser siempre «potencial cliente». Entonces, uno de los límites que emergió en las reuniones de «gateros» fue la demanda de intervención, que hubiera significado pasar directamente a una observación participante. Este punto, en combinación con la imposibilidad de revelar mi identidad como investigador, bloqueó mis posibilidades. No encontré aquí una forma de responder adecuadamente a las demandas de los informantes sin hacerlo desde la impostación o la impostura.

En sentido inverso a lo ocurrido en la primera investigación, mi posición estructural en tanto que varón no suponía aquí una asimetría, pero los modos de la interacción se presentaban más problemáticos en algunos casos. Si el riesgo de la intervención de emociones antes había sido una romantización de los vínculos; en los grupos de «gateros», donde hay posiciones supuestamente compartidas y roles esperados -el «ser varón» como pretendido igualador de las masculinidades-, son las dificultades para construir empatía las que empobrecen los vínculos $\mathrm{y}$, consecuentemente, el conocimiento que puede surgir de ellos. Asimismo, el trabajo de bloquear ciertas emociones y ocultar formas de masculinidad inapropiadas en ese entorno me llevan a la exclusión (o la autoexclusión).

\section{Conclusiones}

Los vínculos con el propio cuerpo siempre involucran procesos arduos. La relación especular con las llamadas ciencias duras y la incorporación de la fantasía del conocimiento «objetivo» y totalizante ha resultado en el intento, siempre fallido, de fabricar una mirada descorporeizada en las ciencias sociales. Esta mirada espejada niega la relación con esos otros y otras, los y las informantes; vínculo de donde emerge no solo el conocimiento, sino el re-conocimiento de la propia posición. Ahora bien, como hemos visto, la asunción de nuestra posición abre nuevos interrogantes.

Mi posición sexo-genérica y mi sexualidad eran puestas en cuestión y desafiadas en ambas investigaciones. Aun cuando lograra salir momentáneamente de los lugares donde se me situaba, nunca resultaba posible suturar un sentido completamente distinto de aquel ligado a la posición de cliente. En ambas investigaciones, ensayé diferentes accesos y confirmé que no solo se trata de tener o no acceso al campo, sino de cómo se entra, quiénes son los o las gatekeepers y cómo eso condiciona la posición que podemos construir en las subsiguientes relaciones de investigación. En ambos casos, los accesos más directos y menos mediados resultaron más trabajosos, pero también más fructíferos.

La escritura de este texto ha estado atravesada por el propio cuestionamiento del lugar de varones cisgénero como enunciadores. En la coyuntura actual, ¿cómo sería posible usar

\section{(c) (1) $(9)$}

Este obra está bajo una licencia de Creative Commons Reconocimiento-NoComercial-SinObraDerivada 4.0 Internacional. 
el self de modo epistemológicamente productivo si la identidad atribuida es de un varón cisgénero heterosexual? La potente propuesta de poner en juego el self, y trabajar desde su condición de «parcial» e incluso contradictorio, se tensiona en un campo donde algunas vertientes del feminismo trazan miradas dicotómicas, reificadoras y esencialistas. Si bien es fundamental recordar constantemente las limitaciones que imponen las posiciones estructurales -por ejemplo, la exposición diferencial al riesgo de violencia-, ello no debería implicar caer en una mirada monolítica. Desde mi propia experiencia, aprender que mi self es parcial implica saber que puedo ser leído como «cliente», aun cuando no sea la identificación que deseo (especialmente cuando esta se halla atravesada por connotaciones sexistas); y así también ser leído como «raro» -o no ser legible- entre otros varones, lo que significa una vulnerabilidad/exclusión.

La mirada romántica y nä̈ve que supone que involucrarse emocionalmente podría mostrar el «self verdadero» y allanar las distancias entre quienes investigan y quienes actúan como informantes, resulta casi tan problemática como la descorporeización y la negación del self del objetivismo. Se hace necesario entonces evaluar, en el contexto particular de cada investigación, cómo y cuáles efectos pueden producir las relaciones de género, clase, raza, entre otras; pues estos no son a priori generalizables, unidireccionales ni homogéneos. Asimismo, es necesario tomar en cuenta los procesos históricos y coyunturales que atraviesan el campo para comprender los sentidos (y confusiones) que marcan los cuerpos, las relaciones de investigación y su circulación de afectos y deseos.

Mantener un balance tomando en cuenta todos estos factores implica un desafío, especialmente cuando aparecen puntos en debate al interior de la comunidad científica. En el marco de la crítica del celibato etnográfico obligatorio - como suele suceder cuando una tendencia surge para contrarrestar a otra- se hicieron algunas valoraciones sobre el papel de la sexualización en la relación con informantes que pecan, no moralmente, sino científicamente. Es decir, pecan de cierto simplismo.

Tal es el caso cuando se conciben a las relaciones sexuales como un modo de establecer una mejor conexión entre nuestro self y el de quienes actúan como informantes. Este planteo es comprensible como una respuesta crítica frente el enfoque que promueve la búsqueda de conocimiento objetivo ligado a una neutralidad de sexo-género y el celibato. Sin embargo, en estas posiciones críticas subyace un sentido unívoco, que naturaliza y homogeneiza las experiencias y los significados de la sexualidad. Resulta fundamental comprender cómo los diversos contextos de investigación pueden dar sentidos distintos a las sexualidades y las prácticas sexuales. Del mismo modo, la llamada identidad de género no es una instancia estable ni coherente, sino un conjunto de posiciones conflictivas y contradictorias, con posibilidad de mutar en diferentes contextos. Por ende, tanto los sentidos atribuidos a las prácticas sexuales o a las emociones expresadas, como el significado de «ser varón» no pueden anticiparse ni definirse por fuera de la trama de interacciones que suceden durante el trabajo de campo.

\section{(c) (1) () $\odot$}

Este obra está bajo una licencia de Creative Commons Reconocimiento-NoComercial-SinObraDerivada 4.0 Internacional. 
En este sentido, investigar sobre comercio sexual me ha planteado frecuentes interrogantes sobre los significados que adquieren las prácticas sexuales: ¿es siempre el sexo, aún consentido, sinónimo de intimidad, de reciprocidad? Comparto la crítica del celibato obligatorio y valoro la puesta en juego del self -que propone Kulick- para desdibujar los límites simbólicos (y corporales) que distancian a quien investiga de quien es informante. Ahora bien, tal como el impacto de las posiciones de sexo-género de quien investiga es relativo a cada investigación, lo mismo sucede con la sexualización o erotización. En el contexto del comercio sexual, hemos de analizar cautelosamente dónde se trazan los límites y en qué lugar quedan emplazadas cuáles prácticas sexuales. La combinación de circulación de afectos con la romantización puede eclipsar la forma en que habitualmente se trazan los límites simbólicos en el comercio sexual, que no suele situar las prácticas sexuales comerciales del lado de la intimidad, sino lejos de ella.

Probablemente buena parte del desafío que nos plantea el deseo erótico no tenga que ver con introducir elementos de la subjetividad en la búsqueda de un dato objetivo, sino con el efecto de obturación que produce el celibato obligatorio: el deseo se torna invisible o transparente como factor condicionante -o como productor- de los vínculos entablados en el campo. Difícilmente se avanzará sobre este punto si al interior de la comunidad científica, en vez de analizar críticamente, nos limitamos a condenar, celebrar o hacer chistes sobre la sexualidad en el campo.

Estas reflexiones implican afrontar nuevas preguntas que no son las que suelen pensarse usualmente en la sección «metodología» de un proyecto de investigación. Para ponderar de qué formas relacionarse afectivamente (o no), mostrarse como persona sexualizada, e incluso si involucrarse sexualmente tiene sentido en un campo, deberá tenerse en cuenta qué factores posicionan a quien investiga y cómo inciden en las construcciones de conocimiento que surgen de las relaciones de investigación. Por ejemplo: ¿qué papel tienen la atracción/seducción, el deseo sexual en el acceso y las estrategias de delimitación del campo? ¿Es posible la resignificación afectiva sin el olvido de las diferencias estructurales? ¿Es siempre más fructífera una conexión empática? ¿Qué efectos producen las discrepancias en los sentidos que construyen, tanto quienes investigan como quienes actúan como informantes, sobre el sexo, sobre sus deseos y los deseos ajenos? Son algunas de las preguntas que siguen abiertas.

\section{Agradecimiento}

Agradezco a Cecilia Varela y Daniel Jones por sus valiosas lecturas y comentarios de una versión inicial de este artículo.

Parte de la investigación fue financiada por un proyecto PICT del FONCYT.

\section{(c) (1) () $(9$}




\section{Referencias}

Adler, Patricia, y Peter Adler. 2001. «The Reluctant Respondent». en Handbook of Interview Research. Context and Method, editado por J. F. Gubrium y J. A. Holstein, 515-535. Thousand Oaks, London, New Delhi: Sage Publications.

Bolton, Ralph. 1995. «Tricks, friends, and lovers Erotic encounters in the field.» en Taboo: sex, identity, and erotic subjectivity in anthropological fieldwork, editado por Don Kulick y Margaret Willson, 140-167. London; New York: Routledge.

Bourgois, Philippe. 1990. «Confronting Anthropological Ethics: Ethnographic Lessons from Central America.» jpeaceresearch Journal of Peace Research 27 (1):43-54.

Bourgois, Philippe. 2010. Entrevista al antropólogo Philippe Bourgois. In Cosecha Roja, edited by Héctor Pavón.

Butler, Judith. 2002. Cuerpos que importan : sobre los limites materiales y discursivos del «sexo», Género y cultura, 11. Buenos Aires: Paidós.

Cowburn, Malcolm. 2007. «Men Researching Men in Prison: The Challenges for Profeminist Research.» The Howard Journal of Criminal Justice 46 (3):276-288. doi: doi:10.1111/j.1468-2311.2007.00474.x.

Dubisch, Jill. 1995. «Lovers in the field Sex, dominance, and the female anthropologist.»en Taboo : sex, identity, and erotic subjectivity in anthropological fieldwork, editado por Don Kulick y Margaret Willson, 29-50. London; New York: Routledge.

Figari, Carlos. 2011. «Conocimiento situado y técnicas amorosas de la ciencia. Tópicos de epistemología crítica.» Coloquio internacional de filosofía y teoría jurídico-social «Enrique Marí», Buenos Aires.

Flood, Michael. 2013. «Negotiating Gender in Mens Research among Men.» en Men, masculinities and methodologies, editado por Barbara Pini y Bob Pease, 64-76. Basingstoke: Palgrave Macmillan.

Fontana, Andrea, y James H Frey. 1994. «Interviewing: the art of science.» en Handbook of qualitative research, editado por Norman Denzin y Yvonna Lincoln. Thousand Oaks: Sage Publications.

Gaspar, Maria Dulce. 1985. Garotas de programa : prostituiçao em Copacabana e identidade social. Rio de Janeiro: J. Zahar.

Gómez, Gregorio Rodríguez, Javier Gil Flores, y Eduardo García Jiménez. 1996. Metodología de la investigación cualitativa, Granada: Aljibe. 
Grenz, Sabine. 2005. «Intersections of Sex and Power in Research on Prostitution: A Female Researcher Interviewing Male Heterosexual Clients.» Signs 30 (4):2091-2113. doi: $10.1086 / 428418$.

Haraway, Donna. 1995. Ciencia, cyborgs y mujeres : la reinvención de la naturaleza. Madrid: Cátedra.

Hochschild, Arlie Russell. 1979. «Emotion Work, Feeling Rules, and Social Structure.» American Journal of Sociology 85 (3):551-575.

Humphreys, Laud. 1974. Tearoom trade: Impersonal sex in public places: Aldine Publishing Company.

Irwin, Katherine 2008. «En el oscuro corazón de la etnografía. Ética y desigualdades en las relaciones íntimas al interior del campo.» Apuntes De Investigación Del Cecyp 0 (12):133-163.

Justo, Carolina, y Santiago Morcillo. 2011. «Posiciones de sexo/género en la configuración de un campo de investigación.» Revista Encuentros Latinoamericanos 11/12 (5):1-8.

Kulick, Don, y Margaret Willson. 1995. Taboo : sex, identity, and erotic subjectivity in anthropological fieldwork. London; New York: Routledge.

Lacombe, Andrea. 2009. «'Tu é ruim de transa!' ou como etnografar contextos de sedução lésbica em duas boates GLBT do subúrbio do Rio de Janeiro.» en Prazeres dissidentes, editado por María Elvira Díaz-Benítez y Carlos Figari. Rio de Janeiro: Garamond Universitaria.

Langarita Adiego, Jose Antonio. 2017. «On sex in fieldwork: Notes on the methodology involved in the ethnographic study of anonymous sex.» Sexualities 22 (7-8): doi: $10.1177 / 1363460717716581$.

Markowitz, Fran. 2003. «Sexualizando al antropólogo: implicaciones para la etnografía.» en Antropología de la sexualidad y diversidad cultural, editado por José Antonio Nieto. Madrid: Talasa Ediciones.

Morcillo, Santiago. 2010. «iIr de putas? Reflexiones en torno a las dimensiones sexuadas de la investigación.» Kula. Antropólogos del Atlántico Sur 3:7-13.

Morcillo, Santiago. 2011. «De cómo vender sexo y no morir en el intento. Fronteras encarnadas y tácticas de quienes trabajan en el mercado sexual.» Revista Latinoamericana de Cuerpos Emociones y Sociedad 7 (3):17-28.

Morcillo, Santiago. 2014. «'Como un trabajo'. Tensiones entre sentidos de lo laboral y la sexualidad en mujeres que hacen sexo comercial en Argentina.» Sexualidad, Salud y 
Sociedad (Rio de Janeiro) 18:12-40. doi: http://dx.doi.org/10.1590/19846487.sess.2014.18.04.a

Morcillo, Santiago. 2017a. «Contrabando de afectos, fugas de capitales y otros desplazamientos. Relaciones de sexo comercial más allá de las fronteras de la prostitución.» Cadernos $\quad$ Pagu $49 . \quad$ doi: https://dx.doi.org/10.1590/18094449201700490015.

Morcillo, Santiago. 2017b. «Las joyas de la familia. Secretos, género y dineros en los vínculos afectivo familiares de mujeres que hacen comercio sexual.» Apuntes de Investigación del CECYP 29:(en prensa).

Morcillo, Santiago, Estefanía Martynoswkyj, y Matias de Stéfano Barbero. 2018. «Una aproximación a los discursos sobre feminismo en varones que pagan por sexo en Argentina.» Sapiens Research 8 (2):54-62.

Newton, Esther. 1996. «My Best Informant's Dress: The Erotic Equation in Fieldwork.» en Out in the Field, editado por Lewin Ellen y Leap William. Chicago: Urbana

Nilan, P. M. 2002. «'Dangerous fieldwork' re-examined: the question of researcher subject position.» Qualitative Research 2 (3):363-386.

O'Connell Davidson, Julia. 2008. «If no means no, does yes mean yes? Consenting to research intimacies.» History of the Human Sciences 21 (4):49-67.

O'Connell Davidson, Julia, y Derek Layder. 1994. Methods, sex, and madness. London; New York: Routledge.

Oakley, Ann. 1981. «Interviewing women: A contradiction in terms.» en Doing feminist research, editado por Helen Roberts, 52-83. London: Routledge.

Oakley, Ann. 2016. «Interviewing Women Again: Power, Time and the Gift.» Sociology 50 (1):195-213. doi: 10.1177/0038038515580253.

Pasini, Elisiane. 2009. «Sexo com prostitutas: Uma discussão sobre modelos de masculinos.» en Prazeres Dissidentes, editado por María Elvira Díaz-Benítez y Carlos Figari. Rio de Janeiro: Garamond Univesitaria.

Pecheny, Mario. 2008. «Introducción: Investigar sobre sujetos sexuales.» en Todo sexo es político : estudios sobre sexualidades en Argentina, editado por Mario Pecheny, Carlos Figari y Daniel Jones. Buenos Aires: Libros del Zorzal.

Pecheny, Mario, Hernán Manzelli, y Alejandro Capriati. 2010. «El papel de los varones en la investigación sobre salud sexual y reproductiva.» IV Congreso ALAP: Condiciones y Transformaciones Culturales, Factores Económicos y Tendencias Demográficas en Latinoamericana, La Habana, 16-19 de noviembre.

\section{(c) (1) $(9)$}

Este obra está bajo una licencia de Creative Commons Reconocimiento-NoComercial-SinObraDerivada 4.0 Internacional. 
Perlongher, Néstor. 1993. La prostitución masculina. El negocio del deseo. Buenos Aires: De la Urraca. Original edition, 1987.

Russo, Gláucia Helena Araújo. 2008. «Rodando a bolsinha: dinheiro e relações de prostituição.» Seminário Internacional Fazendo Gênero 8, Florianópolis/SC, 25 a 28 de agosto.

Sanders, Teela. 2006. «Sexing Up the Subject: Methodological Nuances in Researching the Female Sex Industry.» Sexualities 9 (4):449-468.

Scott, James C. 2000. Los dominados y el arte de la resistencia : discursos ocultos, Colección problemas de México. México: Era.

Walby, Kevin. 2010. «Interviews as encounters: issues of sexuality and reflexivity when men interview men about commercial same sex relations.»Qualitative Research 10 (6):639657.

Warren, Carol A. B. 2001. «Qualitative Interviewing.» en Handbook of Interview Research. Context and Method, editado por J. F. Gubrium y J. A. Holstein, 83-101. Thousand Oaks, London, New Delhi: Sage 